\title{
CHROMITE. PROCESSING AND APPLICATIONS
}

\section{Marius VASILESCU, Mircea DOBRESCU}

Politehnica University of Bucharest, Romania

e-mail: vmarius_sim_pub@yahoo.com

\begin{abstract}
In the paper are shown the history, processing and applications of chromite. Chromite is an oxide of iron and chromium with the chemical composition $\mathrm{FeO} . \mathrm{Cr}_{2} \mathrm{O}_{3}$ and belonging to the spinel group.

Theoretically it contains $46.5 \% \mathrm{Cr}$ and $25.8 \% \mathrm{Fe}$ and their oxides.

The technology of obtaining chromite is based on the principle of gravity separation and agglomeration.

Among the applications we mentioned: - Ferrochrome; - Stainless steel; Nickel chromium alloys; - Nonferrous alloys; - Foundry.
\end{abstract}

KEYWORDS: chromite, processing, applications

\section{Introduction}

Chromite is the only commercially exploited ore of chromium, and is also referred to as "chrome ore" $[1,2]$.

In nature, the ferrous iron is generally replaced partially by magnesium, and the chromium by ferric iron or aluminium, with consequent variations in the $\mathrm{Cr} / \mathrm{Fe}$ ratio. Thus, its composition is represented by the generalized formula $(\mathrm{Fe}, \mathrm{Mg}) \mathrm{O} .(\mathrm{Cr}, \mathrm{Al}, \mathrm{Fe})_{2} \mathrm{O}_{3}$ [3]. It occurs in ultrabasic igneous rocks generally associated with peridotite, pyroxenite, serpentinite and dunite. Its commercial deposits are broadly of two types - podiform and stratiform. The former is generally high-alumina and the latter iron-rich.
Chromite was first mined in Norway in 1820 as a refractory material. In 1903, its mining commenced in Beluchistan, Pakistan, then in Mysore and Singbhum districts, India, in 1907 and 1909 respectively. But the most famous and the largest resources of Orissa state were discovered only in 1943. During the 44 year-period, from 1903 to 1946 , the cumulative total production in the states of then India (i.e., including present Pakistan) was 1.4 million tonnes, out of which about 0.74 million tonnes were in the states belonging to present India.

The production reached the peak figure of about 62000 tonnes in 1937, and thereafter, during the fiveyear period 1942-1946, averaged only 24000 tonnes per year. In India, since independence in 1947, the production profile of chromite was as follows (Table $1)$.

Table 1. Chromite production in India

\begin{tabular}{|c|c|}
\hline Years & Chromite production [t] \\
\hline 1950 & 17000 \\
\hline 1960 & 107000 \\
\hline 1970 & 274000 \\
\hline 1980 & 321000 \\
\hline 1990 & 959000 \\
\hline April, 2000- March, 2001 & 1970000 \\
\hline
\end{tabular}

During the year 2000, the world production stood at 14.6 million tonnes, and India ranked third after South Africa and Kazakhstan.

In India, although a chromite beneficiation plant was in operation in the 1970s, the widespread commercial practice of beneficiation of low-grade chromite is relatively recent, dating back to the 1990s. But it has made a drastic difference to the resource availability of chromite. Chromite concentrate is not an end product, but it is a tradable 
product in the domestic as well as international market.

\section{Technology}

Typically, the technology is based on the principle of gravity separation. The friable and the fine-sized ores are crushed and ground to (-) 150micron size, and the beneficiation process consists of desliming in hydrocyclones, followed by spiralling and tabling [4]. These processes serve to increase the $\mathrm{Cr}_{2} \mathrm{O}_{3}$ content and reduce the $\mathrm{SiO}_{2}$ content, but no appreciable improvement in $\mathrm{Cr} / \mathrm{Fe}$ ratio takes place. Magnetic separator may also be introduced in the circuit for treatment of ferruginous ores to improve $\mathrm{Cr} / \mathrm{Fe}$ ratio. The low-grade lumpy ores containing lots of clay that are not directly usable, are crushed and washed.

The product of beneficiation, i.e. the concentrate, is fine grained, but in conventional metallurgical processes it cannot be directly used [5, 6]. For that purpose, concentrates and also high-grade natural fines are agglomerated into briquettes, sinters, pellets and sintered pellets. Briquettes are made by pressing the fines or without bonding material. This is the simplest and cheapest method of agglomeration, but in many cases, briquettes do not retain their shape under the smelting conditions [7,8].

Sintering is carried out by partial fusion of the corners of the grains, and fluxes (e.g. limestone) are generally added at this stage itself [9]. Pelletizing involves mixing the fines with bentonite (bonding material), fluxing material and coke, and then subjecting the mixture to rotational motion in drum or disc. Sintered pellet is essentially a combination product of pellet and sinter, and is considered superior to the other agglomeration products. For manufacturing this product, green pellets are burnt to a temperature ranging from $1350-1450{ }^{\circ} \mathrm{C}$ in a sintering furnace.

\section{Applications}

\subsection{Ferrochrome}

Taking advantage of the natural association of chromium and iron, ferrochrome - not metallic chromium is added to steel for making stainless steels and other alloys of chromium and steel. This is added to steel as an alloying metal for improving various properties such as resistance to heat, corrosion and abrasion, as well as strength, hardness etc., and the physical and mechanical properties of chromium are taken advantage of [10].

The alloy steel products include low to high carbon steels including stainless steels and tool steels for ordinary level performances. Ferrochrome is classified into six types:

(a) High carbon ferrochrome;

(b) Charge chrome;

(c) Silicochrome;

(d) Medium carbon ferrochrome;

(e) Low carbon ferrochrome;

(f) Exothermic ferrochromium.

Except silicochrome, all the other four types differ from each other mainly by carbon content. These types are discussed as follows.

\subsubsection{High carbon ferrochrome}

The carbon content in the high carbon ferrochrome is in the range of $4-8 \%$, while the chromium and silica contents may vary from $60-70 \%$ and $1-2 \%$ respectively, although $64-66 \% \mathrm{Cr}$ and 5.0$6.5 \% \mathrm{C}$ are relatively more typical. The conventional manufacturing process involves smelting in an electric arc furnace (EAF). Chromite (in the form of natural lumps or agglomerated products) along with coke and some slag-forming materials like limestone, dolomite etc. are charged into the furnace. Some silica and alumina-bearing materials such as quartz, bauxite etc. are also added for balancing the composition and volume of the slag depending on need. Improvements in the process mainly by way of preheating the charge have been carried out with a view to reducing power consumption and cost and to improving metal recovery.

The process is highly power-intensive, the consumption of power being in the range of 4200$5000 \mathrm{kwh}$ per tonne of the product. There is one more technology, namely the plasma arc smelting technology. Plasma arc furnaces are in operation in Sweden and South Africa. In this process, the heat is produced by plasma torches. Its advantage lies in its ability to use ore fines and noncoking coal, but its main disadvantage is the high requirement of electricity.

\subsubsection{Charge chrome}

Charge chrome is a very high carbon low grade ferrochrome. It is actually "charge grade chromium", as it is in this form that chromium is charged into the furnace for stainless steel manufacturing since the development of highly effective decarburization technologies, namely vacuum oxygen decarburization (VOD) and argon oxygen decarburization (AOD). Its carbon-content, as in the case of high carbon ferrochrome, varies up to $8 \%$ - generally $6-8 \%$, but the chromium content is below $60 \%$ and may be as low as 50\%; silica is also high, 3-6\%. Decarburization is critically important in stainless 
steel manufacturing, because carbon combines with chromium to form chromium carbide thus robbing the stainless steel of a portion of the chromium added.

The VOD and AOD technologies achieve decarburization very effectively, and so, lowchromium charge chrome combined with a high degree of decarburization can yield the same grade of stainless steel as high-chromium ferrochrome with a low degree of decarburization. That is how charge chrome has become a cheaper and popular option after the advent of the new decarburization technologies. The process employed for its manufacture is the same as in the case of high carbon ferrochrome.

\subsubsection{Silicochrome}

Ferrochrome silicon or chrome silicide or silicochrome is both an intermediate product used in making low carbon ferrochrome and a final salable product for charging in alloy steel making. Silicochrome is a high-silicon low-iron low-carbon product. In effect, silicon takes the place of a portion of iron. Typically, it contains $35-41 \% \mathrm{Cr}, 35-45 \% \mathrm{Si}$ and $0.05 \% \mathrm{C}$. It can be made by resmelting high carbon ferrochrome with silica and coke or charcoal.

But the most common method of producing it is by smelting in an EAF of charge composed of chromite, silica and coke or charcoal. Since no lime is added, there is no slag, and the silica does not go to form silicate.

In the first method, carbon of the high carbon ferrochrome and the coke is oxidized by the silica and the silicon goes into solid solution with chromium. In the second method, the coke reduces both the chromite and the silica, and the chromium and silicon form the silicochrome [11].

\subsubsection{Medium carbon ferrochrome}

The range of carbon is $1-4 \%$ and that of chromium $65-75 \%$. Simply by blowing oxygen through molten high carbon ferrochrome in a converter and reducing the carbon content, the desired lower range of carbon can be achieved.

\subsubsection{Low carbon ferrochrome}

This is used in making very high quality stainless and other alloy steels meant for special products like chemical-manufacturing and food processing equipment, surgical instruments, cryogenic vessels, nuclear power stations, spaceship components, etc. Carbon should be below $0.5 \%$, and more commonly varies from $0.015-0.05 \%$; chromium
65-75\%; and silicon less than $1 \%$. Low carbon ferrochrome can be manufactured by oxygen refining of high carbon ferrochrome and reducing its carbon content in multiple stages.

But this process is expensive. The common method uses high-silicon low-carbon silicochrome and chromite as the starting materials. The principle essentially consists of smelting the chromite with lime in an open arc furnace producing a chromiumrich chromite/lime slag, and treating this slag with the low carbon high silicon silicochrome. The silicon of the silicochrome goes to react with the lime of the slag to form calcium silicate slag, while the chromium of the silicochrome and that of the slag add up to increase the chromium content of the product i.e., low carbon ferrochrome [12].

\subsubsection{Exothermic ferrochrome}

Exothermic ferrochrome is used when the chilling effect of adding conventional ferrochrome to the molten steel is undesirable. One such product is composed of ferrochrome, a small quantity of ferrosilicon or silicochrome, and sodium nitrate. It is produced in both low and high carbon grades.

\subsection{Stainless steel}

Stainless steel has been dealt with in the chapter on hematite. Chromium is the key element in it. It is defined as an alloy steel containing more than $9 \%$ chromium - with or without other elements. It is characterized by a high degree of resistance to corrosion or oxidation or rusting. In ordinary steels, the initial oxidation forms a loose permeable scale which holds moisture and allows oxygen to diffuse readily and progressively attacking the metal below [13].

In contrast, in stainless steels, the initial oxidation forms a very thin, transparent and highly adherent skin of chromium oxide which, being impervious to oxygen, prevents progressive oxidation of the body of the stainless steel below.

Amongst the other optional elements, nickel is the most important. For manufacturing stainless steel, a mixture of steel, stainless steel scrap, chromium (in the form of ferrochrome) and nickel (optional) is changed into an electric arc furnace (EAF) and smelted. Carbon (the original carbon present in the steel plus the carbon got through the ferrochrome) is an important factor in stainless steel.

It melts in the EAF, and combines with chromium to form chromium carbide thus robbing the stainless steel of a portion of the chromium added. This problem can be overcome by adding ferrochrome containing very low carbon or by adding 
ferrochrome containing high carbon with simultaneous decarburization of the molten bath by argon oxygen decarburization (AOD) and vacuum oxygen decarburization (VOD) technologies.
The aim is to minimize the formation of chromium carbide and maximize the availability of chromium for alloying. Examples of stainless steels are presented in Table 2 .

Table 2. Examples of stainless steels

\begin{tabular}{|c|c|c|}
\hline Chromium content [\%] & Other elements [\%] & Properties/Uses \\
\hline 12 & $0.3 \% \mathrm{C}$ & Hard. Used in table knives \\
\hline 14-18 & $\max .0 .12 \% \mathrm{C}$ & Nonhardenable \\
\hline 14-18 & $\max .0 .12 \% \mathrm{C} ; \min .0 .15 \% \mathrm{Se}$ & Free machinability \\
\hline 16-18 & $0.95-1.20 \% \mathrm{C} ; \max .0 .75 \% \mathrm{Mo}$ & Fully hardenable \\
\hline $23-27$ & $\max .0 .20 \% \mathrm{C}$ & Resistant to scale formation when hot \\
\hline 18 & $\begin{array}{c}18 \% \mathrm{Ni} ; 0.07 \% \mathrm{C} ; 3.5 \% \mathrm{Mo} \\
0.6 \% \mathrm{Ti} ; 2.0 \% \mathrm{Cu}\end{array}$ & $\begin{array}{l}\text { Suitable for applications requiring strong } \\
\text { resistance to chemical attacks by sulphuric } \\
\text { and other acids, and sulphates and other } \\
\text { salts (e.g. chemical equipment) }\end{array}$ \\
\hline $24-26$ & $19-22 \% \mathrm{Ni} ; \max .0 .08 \% \mathrm{C}$ & $\begin{array}{c}\text { Uses requiring resistance to scale and stress } \\
\text { at temperatures as high as } 1000{ }^{\circ} \mathrm{C} \text { (e.g. } \\
\text { staking equipment, furnace parts) }\end{array}$ \\
\hline $16-18$ & $6-8 \% \mathrm{Ni} ; \max .0 .15 \% \mathrm{C}$ & Ferritic. Hardenable \\
\hline$(+) 20$ & Low nickel & $\begin{array}{l}\text { Mixture of austenite and ferrite (duplex); } \\
\text { can be strengthened by addition of nitrogen. } \\
\text { Very high-performance stainless steel, } \\
\text { strong, with high corrosion resistance and } \\
\text { very good weldability. Used in appliances, } \\
\text { in nuclear stations, in fabrication of large } \\
\text { diameter tubes, in coins. }\end{array}$ \\
\hline $18-20$ & $8-12 \% \mathrm{Ni} ; \max .0 .8 \% \mathrm{C}$ & Austenitic; superior corrosion resistance \\
\hline $18-20$ & $8-12 \% \mathrm{Ni} ; \max .0 .3 \% \mathrm{C}$ & $\begin{array}{l}\text { It resists the formation of chromium } \\
\text { carbide around crystal boundaries. }\end{array}$ \\
\hline $16-18$ & $\begin{array}{l}10-14 \% \mathrm{Ni} \text {; max. } 0.8 \% \mathrm{C} ; 2- \\
3 \% \mathrm{Mo}\end{array}$ & Superior corrosion resistance \\
\hline $17-19$ & $\begin{array}{l}9-12 \% \mathrm{Ni} ; \max .0 .08 \% \mathrm{C} ; 5- \\
\text { times carbon-content } \mathrm{Ti}\end{array}$ & $\begin{array}{l}\text { It resists the formation of chromium } \\
\text { carbide around crystal boundaries. }\end{array}$ \\
\hline $17-19$ & $\begin{array}{l}\text { 9-13\% Ni; max. } 0.08 \% \mathrm{C} ; 10- \\
\text { times carbon-content } \mathrm{Nb}\end{array}$ & $\begin{array}{l}\text { It resists the formation of chromium } \\
\text { carbide around crystal boundaries. }\end{array}$ \\
\hline 17 & $4 \% \mathrm{Ni} ; 3.5 \% \mathrm{Cu}$ & Martensitic. Used in aircraft industry \\
\hline 20 & $34 \% \mathrm{Ni} ; 3.5 \% \mathrm{Cu} ; 2.5 \% \mathrm{Mo}$ & $\begin{array}{l}\text { Austenitic; highly resistant to the action of } \\
\text { sulphuric acid. }\end{array}$ \\
\hline 21 & $0.3 \% \mathrm{Ti}$ & $\begin{array}{l}\text { Nickel-moly free stainless steel. Resistant } \\
\text { to corrosion, malleable, low cost }\end{array}$ \\
\hline
\end{tabular}

\subsection{Nickel chromium alloys}

These alloys are rich in nickel with chromium and other metals.

Nickel and chromium readily dissolve.

Such alloys are very highly resistant to corrosion, acids alkalis and heat. Some of the grades possess good electrical resistivity, and some others are resistant to creep at high temperatures. There are five grades:
- Inconel containing $76 \% \mathrm{Ni}, 15.8 \% \mathrm{Cr}$, $7.2 \% \mathrm{Fe}, 0.2 \% \mathrm{Si}, 0.1 \% \mathrm{Cu}$ and $0.04 \% \mathrm{C}$; it is resistant to corrosion at high temperatures. It finds application in engineering goods for use in severely corrosive environment at high temperatures.

- Incoloy containing $32 \% \mathrm{Ni}, 20.5 \% \mathrm{Cr}$, $46 \% \mathrm{Fe}, 0.3 \% \mathrm{Cu}$ and $0.04 \% \mathrm{C}$; it resists oxidation, carburization, corrosion and sulphur attack at high temperatures.

- Nimonic containing $58 \% \mathrm{Ni}, 20 \% \mathrm{Cr}$, $17 \% \mathrm{Co}, 2.5 \% \mathrm{Ti}, 1.5 \% \mathrm{Al}$ and $0.13 \%(\max ) \mathrm{C}$; it is 
creep resistant at temperatures up to $920^{\circ} \mathrm{C}$. It is used in gas turbine blades and discs, hot-working tools.

- Nimocast containing $76 \% \mathrm{Ni}, 19 \% \mathrm{Cr}$, $0.3 \% \mathrm{Mn}, 0.3 \% \mathrm{Cu}, 0.4 \% \mathrm{Ti}, 0.3 \% \mathrm{Al}, 1.5 \% \mathrm{Co}$ and $0.1 \% \mathrm{C}$; it resists oxidation at temperatures up to 1100 ${ }^{\circ} \mathrm{C}$. It is a casting alloy.

- Nichrome with two sub-grades namely, "chronin" containing $80 \% \mathrm{Ni}$ and $20 \% \mathrm{Cr}$ or "ferrochronin" containing $60 \% \mathrm{Ni}, 15 \% \mathrm{Cr}$ and $25 \% \mathrm{Fe}$. Both possess high electrical resistivity and resistance to thermal shocks due to repeated heating and cooling. They are used in heating elements of electric furnaces, toasters, stoves, etc. The former is suitable for use at temperatures up to $1150{ }^{\circ} \mathrm{C}$ and the latter, up to $800{ }^{\circ} \mathrm{C}$.

\subsection{Other alloy steels}

These can be made by adding some chromite directly to steel furnaces along with ferrosilicon as reductant or, more commonly, by adding a suitable type of ferrochrome depending on the composition of the alloyed product aimed at. Some important types of products are:

\subsection{Chromium metal}

Until 1950s, metallic chromium used to be made by the aluminothermy route. It involved smelting of chromic oxide. The grade of the metal was $97 \%$ (min) $\mathrm{Cr}$ and $1 \%(\max ) \mathrm{Fe}$. In this method, chromite is first oxidized by air in molten alkali to yield sodium chromate $\left(\mathrm{Na}_{2} \mathrm{Cr}_{2} \mathrm{O}_{4}\right)$, which is converted to $\mathrm{Cr}_{2} \mathrm{O}_{3}$ (chrome oxide green) by dissolving it in water. The oxide is then precipitated and reduced by carbon. The metal thus obtained is further reduced and refined by aluminium powder. But the method is costly. Alternatively, the final refining can be done by using silicon as reductant. The common method nowadays is by electrolysis.

This involves dissolution of $\mathrm{Cr}_{3} \mathrm{O}_{3}$ in sulphuric acid to give an electrolyte. In a process developed by the US Bureau of Mines, the electrolyte was made from high carbon ferrochrome. The purity of electrolytic chromium is $99 \%$ ( $\mathrm{min}$ ) Cr. There are three types of chromium metal produced: 9-11\% C;

- High carbon, containing $87 \%(\mathrm{~min}) \mathrm{Cr}$ and

- Low carbon, containing 97\% (min) $\mathrm{Cr}$ and $0.1 \%(\max ) \mathrm{C}$; $0.2 \% \mathrm{C}$.

- Electrolytic, containing $99.5 \% \mathrm{Cr}$ and

\subsection{Nonferrous alloys}

Since there is no iron in such alloys, ferrochrome cannot be used as additive. Instead, chromium metal is used. Stellite, chromin are example of such alloys.

\subsection{Foundry}

The use of chromite sand as moulding medium was first practised in the 1950s in South Africa, for producing manganese and steel castings. It is used when a refractory medium is required as in the case of casting of metals with high melting point, where siliceous sand is not suitable.

The high fusion temperature, resistance to thermal shocks and chilling effect of chromium are the main criteria. Besides, the brittleness and uneven fracture make it easy to crush into angular grains.

The high fusion temperature and resistance to thermal shocks prevent the casting from damaging the moulding surface. The chilling effect facilitates the quick solidification of the casting. Preparation of chromite for this use involves crushing, washing and screening, and freeing it from impurities such as silica, talc, serpentine and asbestos by heavy media separation.

\subsection{Chrome-plating}

Chrome-plated surfaces have a bright bluish white finish with a high reflecting power. Such surfaces also possess a fair degree of electrical resistance. The corrosion resistance, high reflecting power and relatively low electrical conductivity of chromium are the chief criteria.

But Chromium plating is not just for imparting a durable and decorative finish to articles of common use [14], it is also done to resize machine parts by thickening their surfaces, to improve wear resistance of tools, and to line pump rods, engine cylinders and machine gun barrels. Chrome-plating is achieved by precipitation of chromium in an anodizing bath containing chromic acid through electrolysis.

\subsection{Metallization}

Chromium is used to metallize surfaces to make them corrosion-resistant [15]. Metallization is the process in which very small globules of a liquid metal are blown by a spray gun and sprayed on other metal surfaces to improve corrosion or wear resistance. The surface to be sprayed is first roughened by roughmachining or rough-grinding. The molten globules of metal, on being sprayed, immediately solidify and interlock by flattening. 


\subsection{Chemicals}

The important chemicals are sodium dichromate, lead chromate, chromates of zinc and barium, chromic oxide, chromic acid, basic chromium sulphate, potassium dichromate, hydrated sodium chromate, potash-chrome alum and chromium dioxide.

Sodium dichromate $\left(\mathrm{Na}_{2} \mathrm{Cr}_{2} \mathrm{O}_{7}\right)$ is the mother chemical from which most of the other chemicals are derived. It is produced directly from chromite. Ground chromite is first roasted with soda ash and lime in the presence of oxygen to separate the impurities iron, alumina and silica of the ore, and to yield a mixture containing sodium chromate, which is extracted by quenching in water and leaching.

It is treated with sulphuric acid to finally produce a commercial grade of sodium dichromate. Both the intermediate product sodium chromate and the final product sodium dichromate are important industrial chemicals used for leather-tanning and for organic chemical oxidation, for bleaching of oils, fats and waxes, and as additive in drilling mud to prolong the life of drill strings.

Lead chromate $\left(\mathrm{PbCrO}_{4}\right)$ in pure form supplies the chrome reds. By mixing it with other substances the painters make various yellow pigments. When mixed with Prussian blue, it yields green pigments. It is a natural occurring mineral also - "crocoite" or "red lead", and the Siberian red lead is prized as a red pigment for oil. But the synthetic chemical, being more easily available and cheaper, is more popular.

Chromates of zinc and barium $\left(\mathrm{ZnCrO}_{4}\right.$ and $\mathrm{BaCrO}_{4}$ ) are extensively used for colouring linoleum, rubber and ceramics.

One of chromic oxide $\left(\mathrm{Cr}_{2} \mathrm{O}_{3}\right)$ products called "chrome green" contains $97-99 \%$ of this chemical, and is a green pigment used in paints particularly for outside applications required to withstand severe weather conditions. Other uses include manufacture of linoleum, ceramic glazes, coloured glass, stainless electrode, polishing material and chromium metal [15].

Chromium acid $\left(\mathrm{CrO}_{2}(\mathrm{OH})_{2}\right)$ solutions are used in chrome-plating, in anodizing of aluminium and in protection of magnesium-based alloys. It is also used as oxidizing agent and as laboratory reagent.

Basic chromium sulphate $\left(\mathrm{CrOHSO}{ }_{4} \cdot \mathrm{Na}_{2} \mathrm{SO}_{4}\right)$ is used in leather tanning to obtain what are called "wet blue chrome skins". Chrome-tanned leather has high wear resistance. This chemical is also used in the manufacture of "mineral khaki".

Potassium dichromate $\left(\mathrm{K}_{2} \mathrm{Cr}_{2} \mathrm{O}_{7}\right)$ is mainly used in the manufacture of safety matches and explosives. Other uses include printing ink, synthetic perfumery, adhesives, engraving and lithography, photography and film processing.
Hydrated sodium chromate $\left(\mathrm{Na}_{2} \mathrm{CrO}_{4} .4 \mathrm{H}_{2} \mathrm{O}\right)$ is used as an anticorrosive salt in cooling water and chilled brine systems, and as a component in inhibitor formulations.

Potash-chrome alum $\left(\mathrm{K}_{2} \mathrm{SO}_{4} \cdot \mathrm{Cr}_{2}\left(\mathrm{SO}_{4}\right)_{3} .2 \mathrm{H}_{2} \mathrm{O}\right)$ is used for fixing bath in photography, as a mordant in textile industry, and for leather tanning.

Chromium dioxide $\left(\mathrm{CrO}_{2}\right)$ finds use in high quality magnetic audio and video recording tapes.

\section{Conclusions}

In a time of sophisticated and expensive technologies, even if chromite needs simple technology and is a simple oxide of iron, the importance of this oxide is increasing, watching the production profile and applications.

The technology of manufacturing is also very simple and with low cost.

The advantages offered by chromite (in different forms) properties are:

- Machinability;

- Resistance;

- Corrosion resistance to the attack of sulphuric acid.

\section{References}

[1]. Zhang W., Zhang P., Liu F., Simultaneous oxidation of $\mathrm{Cr}(\mathrm{III})$ and extraction of $\mathrm{Cr}(\mathrm{IV})$ from chromite ore processing residue by silicate-assisted hydrothermal treatment, Chemical Engineering Journal, vol. 371, p. 565-574, 2019.

[2]. Mishra U., Chandroth A., Basantaray A. K., Assesing chromite ore processing residue (COPR) waste dump site using electrical resistivity tomography (ERT): a case study from Umaran, Kanpur, India, Environmental Monitoring and Assessment, vol. 191, issue 8, 2019.

[3]. Gervilla F., Asta M. P., Fanlo I., Diffusion pathways of $\mathrm{Fe}^{2+}$ and $\mathrm{Fe}^{3+}$ during the formation of ferrian chromite: a mu XANES study, Contributions to Mineralogy and Petrology, vol. 174, issue 8, 2019.

[4]. Song Y., Li J., Peng M., Identification of Cr(VI) speciation in ferrous sulfate-reduced chromite ore processing residue (rCOPR) and impacts of environmental factors erosion on $\mathrm{Cr}(\mathrm{VI})$ leaching, Journal of Hazardous Materials, vol. 373, p. 389-396, 2019.

[5]. ***, ASM Handbook, vol. 9, Metallography and Microstructures, ASM International, Materials Park, OH, 2004.

[6]. Su B., Hu Y., Teng F., Light Mg isotopes in mantle-derived lavas caused by chromite crystallization, instead of carbonatite metasomatism, Earth and Planetary Science Letters, vol. 522, p. 7986, 2019.

[7]. Steyn A., Kemper C., Schuer T., Zietsman J., Weisweiler E., Understanding the energy consumption of melt-ing chromitelime mixtures, Proceedings of EMC, p. 1, 2019.

[8]. Muhammad F., Xia M., Li S., The reduction of chromite ore processing residues by green tea synthesized nano zerovalent iron and its solidification/stabilization in composite geopolymer, Journal of Cleaner Production, vol. 234, p. 381-391, 2019.

[9]. Camalan M., Hosten C., Assessment of grinding additives for promoting chromite liberation, Minerals Engineering, vol. 136, p. 18-35, 2019.

[10]. ***, ASM Handbook, vol. 1, Properties and Selection: Iron, Steels, and High-Performance Alloys, ASM International, Materials Park, OH, 1990. 


\section{THE ANNALS OF “DUNAREA DE JOS” UNIVERSITY OF GALATI \\ FASCICLE IX. METALLURGY AND MATERIALS SCIENCE \\ №. 1 - 2019, ISSN 2668-4748; e-ISSN 2668-4756 \\ Article DOI: https://doi.org/10.35219/mms.2019.1.02}

[11]. Pakzad E., Ranjbar Z., Ghahari M., Synthesized of octahedral cupper chromite spinel for spectrally selective absorber (SSA) coatings, vol. 132, p. 21-28, 2019.

[12]. Li C., Barasa G. O., Zerihun G., Structure and magnetic switching effect in iron-doped europium chromite ceramics, Journal of Alloys and Compounds, vol. 787, p. 463-468, 2019.

[13]. ***, ASM Handbook, vol. 2, Properties and Selection: Nonferrous Alloys and Special-Purpose Materials, ASM International, Materials Park, OH, 1991.

[14]. Farrelly L., Basic Architecture - Construction and Materiality, AVA Publishing SA, 2009.

[15]. Chatterjee K. K., Uses of Metals and Metallic Minerals, New Age International (P) Ltd. Publishers, 2007.

[16]. Duggal S. K., Building Materials $3^{\text {rd }}$ Edition, New Age International (P) Ltd. Publishers, 2008. 